\title{
INFLUENCE OF ENVIRONMENTAL FACTORS ON ENTOMOPATHOGENIC MICROORGANISMS WITH POTENTIAL AS BIOLOGICAL CONTROL AGENTS - minireview
}

\author{
Ana-Cristina Fătu*, Cristina-Maria Lumînare, Daniel Cojanu, Mihaela-Monica Dinu
}

Research-Development Institute for Plant Protection

*correspondence address:

Research-Development Institute for Plant Protection

Bd. Ion Ionescu de la Brad no. 8, Bucharest, Romania

cristina.fatu@icdpp.ro

http://www.doi.org/10.54574/RJPP.13.15

\begin{abstract}
The entomopathogenic fungi play an important role in suppressing the natural population of insect pests. A number of these microorganisms are developed and commercialized as mycoinsecticides for controlling arthropod pests in agriculture and forestry. A wide range of factors and the interactions between them can affect the persistence and survival of entomopathogenic microorganisms; understanding of these factors is indispensable for the successful use of microbiological control agents, in conditions of economic and ecological efficiency. The influence of some of these factors on fungal development and fate in soil and on plants has been studied by a number of authors for several entomopathogenic hyphomycetes used in biological control programs. The aim of this study was to summarize a few aspects about the abiotic and biotic factors that influence the biological activity of entomopathogenic microorganisms. The following environmental factors are presented: light, temperature and humidity, soil, microorganisms, wind and precipitation.
\end{abstract}

Key words: environmental factors, persistence, entomopathogenic

\section{INTRODUCTION}

Knowledge of the ecological potential of entomopathogenic microorganisms is essential for their efficient use in ecological plant protection systems. The insecticidal activity of entomopathogenic microorganisms depends, directly or indirectly, on environmental conditions; microbial growth and biological activity depend on numerous biotic and abiotic factors. Environmental conditions such as: temperature, humidity, nutrient intake etc. must be optimal for the microbiological potential to manifest. The entomopathogenic microorganisms used in the practice of plant protection do not exist in nature in the ideal conditions that we maintain in the laboratory. The study of the factors that, in nature, can influence their biological activity has a great practical importance, for establishing the modalities of application of the microbiological control agents in the biological control of insect pests (Jaronski, 2010). Ecological factors act on entomopathogenic microorganisms, either directly, favoring the appearance of adaptive changes: quantitative (metabolism changes), or qualitative (prolongation of some stages), or indirectly, changing the density of insect populations or their geographical distribution.

Regarding the influence of different ecological factors, entomopathogenic microorganisms have tolerance limits, between which there is an ecological optimum. In other words, an ecological factor absent or reduced below a critical minimum, or, on the contrary, far above the maximum tolerable level, thus becoming a limiting factor, conditioning the possibility of the microorganism to successfully invade a certain habitat and, implicitly, aggressiveness towards the host insect. Moreover, in nature, the interactions between two or more environmental factors can change the limits of tolerance to these factors. 
The effectiveness of the application of biological treatments in insects control also depends on the ecological features of microorganisms; their ability to populate different habitats characterized by more or less large variations of ecological factors explain their geographical distribution, survival and spread in the habitats.

Environmental factors directly or indirectly affect the persistence and survival of entomopathogenic microorganisms (Fuxa, 1987). Key factors affecting the persistence and survival of entomopathogenic microorganisms are temperature, moisture, light, natural antagonism, artificial antagonism (in terrestrial habitats), respectively temperature, humidity / water retention capacity, soil type, natural antagonism, artificial antagonism, oxygen concentration, microbiota (in underground habitats).

The natural mortality induced by environmental factors in populations of microorganisms, can have very high values, with impact on their spatial distribution in different habitats. To compensate for this effect, many entomopathogenic microorganisms produce large amounts of infectious propagules (spores, conidia) or various forms of structures adapted to environmental conditions: hyphae, chlamydospores, resistance spores, sclerotia, macrocyclic conidia (Fuxa, 1987; Tanada \& Kaya, 1993). These epizootic phenomena are based on the existence of favorable biocenotic interactions between the host insect and the pathogen, their ecological management being the basis for the use of entomopathogenic microorganisms in the practice of biological plants protection. The various infectious structures of entomopathogenic microorganisms are produced on a commercial scale in the form of microbial biopesticides that colonize target habitats (Ruiu, 2018). Is the reason why the objective of a strategy for inundative use of entomopathogenic bioproducts is to release, uniformly, a large amount of entomopathogenic inoculum, with high virulence and conditioned in a form that ensures its survival. Understanding the environmental factors that influence the persistence and survival of entomopathogenic microorganisms is indispensable for the successful use of microbiological control agents, in conditions of economic and ecological efficiency.

The aim of the present review is to summarize the data on the influence of the following environmental factors: light, temperature and humidity, soil, microorganisms, wind and precipitations on the entomopathogenic microorganisms used as biological control agents.

Light. Light is an important factor in the biology of most microorganisms. For example, some hyphomycetes produce stromata or synemata-like formations that are attracted to light as a stimulator for sporulation. Aschersonia sp. (Hypocreales: Clavicipitaceae) produces conidiogenic cells in highly pigmented pycnidia to protect themselves from light. Solar radiation, particularly the UV-B component, negatively affects survival of entomopathogenic fungi in the field (Fernandes et al., 2007); natural sunlight (290-400 nm) affects the survival of entomopathogenic fungus conidia applied to leaves or other substrates (Fuxa, 1987). The spores produced by phycomycetes fungi, as well as most entomophthorales species are more sensitive to the effect of sunlight than the conidia produced by ascomycetes and deuteromycetes fungi. Isolates belonging to the same species show different tolerance to the effect of sunlight (Fargues et al., 1996). Fernandes et al. (2007) presented a preliminary trial with three Beauveria bassiana isolates at several UV-B dosages, resulting high variability in tolerance to UV-B radiation among the B. bassiana isolates (low, medium, high UV-B tolerance), ranging from virtually zero tolerance to almost $80 \%$ tolerance. The authors also found negative effects on virulence, by delaying the germination of conidia. Inglis et al. (1993) found that conidia of B. bassiana are rapidly killed by solar radiation under field conditions. 
In general, the half-life for the spores of most entomopathogenic fungi exposed to simulated sunlight is 1 to 4 hours. Experiments performed by Carruthers et al. (1988) with Entomophaga grylli demonstrated that both the duration and intensity of simulated light interact, resulting in a decreasing exponential curve, related to the viability of spores. In field conditions, there were differences of the order of $7 \times 10^{2}$ in the loss of viability of the spores, between lands exposed to the sun and shaded lands. Some authors found that the half-life of fungal conidia under natural conditions is 3-4 hours although others observed a half-life of approximately one to six days (Roberts and Campbell, 1977; Braga et al., 2001; Inglis et al. 1997; Sabbahi et al., 2008). In a review on the efficacy of Metarhizium anisopliae var. acridum against the desert locust, Van der Valk (2007) stated that persistence measured as insect efficacy, may be as long as 8-14 days, at least in the case of $M$. acridum, under semiarid conditions. Exposure of the leaf surface also influences the survival of entomopathogenic microorganisms, the spores surviving a longer time on the abaxial surface, compared to the adaxial one. Experiments conducted by Farques et al. (1988) with Nomuraea rileyi led to the conclusion that, in full sun, the half-life of conidia is 3.6 hours, compared to over 40 hours in the shade. By blocking the wavelength at $400 \mathrm{~nm}$, the half-life of conidia decreased 4-fold compared to exposures at wavelengths of $320-2500 \mathrm{~nm}$. Applying a predictive calculation model, the authors concluded that the viability of conidia is reduced 10,000 times after 7 days in full sun, compared to the decrease of only 100 times in shady conditions. Ignoffo and Garcia (1992) reported that fungal species with pigmented conidia are more resistant than those with less pigmented conidia when exposed to sunlight. According to Bell (1974), the fungus $B$. bassiana loses its infection ability when subjected to direct sunlight for three hours.

Temperature and humidity. Temperature and humidity, the two essential ecological factors, interfere with their action on the entomopathogenic fungi. There are optimal conditions of temperature and humidity that ensure the lowest mortality rate, the highest fertility or the fastest development of organisms, insects being the most studied from this point of view. Soil moisture and water in interaction with temperature are of great importance, on the one hand, for maintaining viability and activity, and on the other hand, for migrating or dispersal of fungi and insects. The survival, germination and growth of B. bassiana in the soil are strongly influenced by the humidity, and the effect of temperature on the stability and survival of conidia depends on soil moisture. Increased humidity reduces the amount of oxygen available, while increasing the amount of carbon dioxide. The concentration of oxygen and carbon dioxide in the soil play an important role in determining the activity, density and diversity of organisms in different soil types. The progressive evaporation of water from the soil followed by its drying causes the death of insects and microorganisms in the soil or prevents their movement.

Studies on the influence of temperature on the infectious process have established that the role of temperature in the onset and evolution of the pathological process is important. For example, if in slow-growing insects the most favorable conditions for the development of cryoptogamic infection correspond to a temperature close to the optimum temperature of entomopathogenic fungi. Studies on Leptinotarsa decemlineata, a fast-growing insect, proved that the thermal level of the parasitic complex is lower than the optimum temperature for the host and pathogen (Andrei, 1998). The temperature acts on the host's functions, changing the rhythm of development and succession of attacks. It is even appreciated that in nature temperature may be the essential limiting factor in the contamination of insects with rapid larval development, although this role is generally attributed to humidity. Experimental data providing the importance of the temperature in the laboratory Beauveria bassiana bioassay procedure, using Plodia interpunctella as host insect are presented by Fatu et al. (2010). 
Temperature and humidity not only affect survival and virulence of entomopathogenic fungi, but also influence their host-pathogen interaction (Kiewnick, 2006). Different entomopathogenic microorganisms have different values of optimal temperatures for growth, development, pathogenesis, survival and spread in the environment. Most entomopathogenic microorganisms are mesophilic, the optimum temperature being between 10 and $30^{\circ} \mathrm{C}$. From the point of view of the use of microorganisms in biological control, it should be noted that the phenomena that depend on temperature - pathogenesis and infectivity - take place better at the optimum temperature than at lower temperatures; in some cases, although the reduction in temperature increases the duration from the time of infection to the death of the insect, the final mortality rate induced by the target insects is not reduced. Optimal temperatures for the survival of microbiological control agents differ from one taxon to another. We exemplify with entomopathogenic fungi, respectively with entomophtoral spores that are more sensitive than those of most deuteromycetes.

In general, temperatures above $35^{\circ} \mathrm{C}$ inhibit the growth and development of entomopathogenic fungi. B. bassiana and $M$. anisopliae conidia have a mortality point $<15$ minutes at $40^{\circ} \mathrm{C}$. Resistance spores of entomophthorals are more resistant to high temperatures, tolerating temperatures of $80^{\circ} \mathrm{C}$ for an hour or more. Below $4^{\circ} \mathrm{C}$, microorganisms survive, but rarely multiply. The conidia of most deuteromycetes retain their viability for long periods of time, at $20^{\circ} \mathrm{C}$ or even less. Yip et al. (1992) and McCammen \& Rath (1994) established that the optimal temperature for conidia germination is very different, in the case of $M$. anisopliae strains isolated from different temperate regions, depending on their origin, being between 2.5 and $37^{\circ} \mathrm{C}$ (heat-active and meso-thermoactive groups). For $B$. bassiana, the optimum temperature is $23-28^{\circ} \mathrm{C}$, the minimum $5-10^{\circ} \mathrm{C}$ and the maximum about $30-38^{\circ} \mathrm{C}$, depending on the isolates. Some african isolates have an optimum temperature of 20 to $30^{\circ} \mathrm{C}$, while some isolates from subantarctic soils germinated at $5^{\circ} \mathrm{C}$ (Zimmermann, 2007). Fatu et al. (2015) found that the optimum temperatures for germination of three romanian strains of B. brongniartii ranged between 15.5 and $25^{\circ} \mathrm{C}$ and that temperatures above $28^{\circ} \mathrm{C}$ affects negatively the germination. Atmospheric temperature between $20^{\circ} \mathrm{C}$ and $30^{\circ} \mathrm{C}$ did not limit the growth and sporulation of $N$. rileyi. On the other hand, since the fungus will not grow below $15^{\circ} \mathrm{C}$ and sporulate above $30^{\circ} \mathrm{C}$, long periods at these extreme may limit both the initiation and development of epizootics (Ignoffo et al., 1976). Fargues et al. (1997) found that the upper threshold for $65 \mathrm{~B}$. bassiana isolates differed: 50 isolates had an upper threshold of $35-37^{\circ} \mathrm{C}, 12$ isolates had a threshold of $32-35^{\circ} \mathrm{C}$, and one isolate had a threshold of $30-32^{\circ} \mathrm{C}$.

In terms of relative humidity and /or water content, this is a factor that particularly affects the ability to survive, spread in the environment and produce diseases in insects (germination of infectious propagules on the cuticle of insects, formation of reproductive structures on the surface of insects) by entomopathogenic microorganisms. In the case of entomopathogenic fungi, humidity affects persistence and survival in other ways, the effects of temperature and humidity being closely correlated. Thus, some fungi can tolerate extreme temperatures if the humidity is high, or if the condensation phenomenon prevents water loss. In vitro experiments have proven the impact of different relative humidities on growth and sporulation of entomopathogenic fungal isolates of Beauveria species (Padmini et al., 2010). Luz \& Fargues (1997) found that humidity requirements for conidial germination of $B$. bassiana are over $90 \%$. In contrast, incubation of conidia at relative humidities over $29.8 \%$ was found favorable for germination of some romanian strains of B. brongniartii (Fatu et al, 2015). With all this, in vitro systems to assess the effect of temperature and humidity on spore germination should be considered because of the differences in composition, availability and distribution in nutrients in comparison with living insects (Khachatourians, 1991). 
Humidity conditions favor the onset of fungal epizootics. Steinkraus \& Slaymaker (1994) studying aspects related to sporulation, spore release and conidia formation in Neozygites ash trees, established that moisture affects host rehydration and consequently the release of conidia. At 35 and $85 \%$ relative humidity, no conidia were produced on the fungus infected with the fungus. Matewele et al. (1994) developed methods in which the action of water in the culture medium for M. anisopliae was reduced to evaporation, which led to the selection of mutants capable of germinating and growing at lower humidity values than the original strains. It was also found that some selected mutants had higher insecticidal activity (virulence) than the original strains.

Soil. The soil is a natural source of insects contaminated with entomopathogenic microorganisms; they die in the soil or on the leaves and reach the soil surface. In general, soil entomopathogenic microorganisms are protected against dehydration, ultraviolet rays and extreme temperatures; however, their spread is periodic and reflects a binomially negative aggregate spatial distribution. This spread suggests that many entomopathogenic microorganisms do not proliferate abundantly in the soil, but remain in close proximity to their hosts, at relatively low densities, under natural conditions. The predominant species of entomopathogenic fungi that live in the soil produce hydrophobic conidia and infectious propagules that attach to the insect epicuticle through contact. If the source of infection remains only on the surface of the soil, only insects that come in contact with this surface will be exposed to contamination. Conversely, if the pathogenic inoculum is in the depths of the soil, where there are no insects, the infection will not occur. Numerous species of insects that have stages of development in the soil, develop on the surface of the cuticle a specific microflora, which gives them protection against entomopathogenic microorganisms.

Soil texture can influence the sporulation and efficiency of entomopathogenic microorganisms, contact with its host, persistence and density in the soil (Inglis et al., 2001, Jaronsky, 2010, Andrei, 1998). Soil moisture effects are mediated by soil texture via porosity (Jaronsky, 2010) which can affect the vertical movements, availability, and survival of the conidia of B. bassiana, M. anisopliae and V. lecanii (Inglis et al., 2001). Sandy-textured and soils low in organic matter tend to retain fewer propagules than clay-textured and organic soils (Ignoffo et al., 1977; Storey \& Gardner, 1988; Keller \& Zimmermann, 1989).

The optimum temperature necessary for the persistence and survival of entomopathogenic microorganisms in the soil varies depending on the strain, soil type, soil moisture and natural antagonists. McCammon \& Rath (1994) identified strains of $M$. anisopliae that are virulent at $5^{\circ} \mathrm{C}$ and persist for 2 years. Studdert \& Kaya (1990) showed that the conidial persistence of the $B$. bassiana fungus increases with the decreases of temperature and also when soil moisture is close to saturation. Persistence decreases rapidly at a temperature of $30^{\circ} \mathrm{C}$, the temperature of $50^{\circ} \mathrm{C}$ being lethal. This relationship between soil water potential, temperature and persistence of conidia in different soils was demonstrated by Studdert \& Kaya (1990) who performed tests on B. bassiana. When conidia were subjected to a water potential ranging from zero to $-10 \mathrm{bar}$, the half-life was extended to $-10 \mathrm{bar}$ and decreased with increasing water in the soil. At a saturation of -0.3 bar, the conidia were recovered in all treatments, after two weeks, and after 5 weeks, they were not found. The halflives of all conidia at these water potentials were less than a week. With the decrease of the water potential from values between -0.3 and -10 , the half-life of the conidia increased faster at $16^{\circ} \mathrm{C}$ than at $28^{\circ} \mathrm{C}$ in both soils, and much faster on clayey sand than on peat. In conclusion, the half-life of conidia reached values of 36.3 and 15.2 weeks at $16^{\circ} \mathrm{C}$ and -10 bar, in clayey sand, respectively peat. Conidia mixed in soil and subjected to a temperature variation from 20 to $50^{\circ} \mathrm{C}$ survived the longest, at $10^{\circ} \mathrm{C}$. The half-life decreased with 
increasing temperature, from 10 to $50^{\circ} \mathrm{C}$ until there were no recoveries of conidia kept for 2 weeks, at $50^{\circ} \mathrm{C}$. At lower temperatures, the survival of conidia in the soil was significantly higher in clayey sands than in peat. Soil moisture also influences the evolution of mycoses. In the case of the fungus $B$. bassiana, at a constant density of conidia, mycosis caused by the newborn larvae of Diaprepes sp. they recorded a decline in dry soil $(<2 \%)$, respectively an increase in water-saturated soil ( $>18 \%)$.

An important factor that should be considered in conidial longevity is the moisture fluctuations at the surface of the soils of an agricultural field, which is more serious that temperature and humidity when the fungus it is applied in the crust of the soil (Jaronski, 2007).With all this, different fungal isolates may respond differently to different soil types and moisture levels.

Microorganisms. The microorganisms that naturally populate the soil, as well as their secondary metabolites function as antagonists in certain soil types, influencing both the infectivity and the survival of the microorganisms. Soil microflora is a major factor in the survival of conidia in the soil, as it can have an adverse effect on the effectiveness of entomopathogenic fungi in the field. Natural habitats are populated by a variable number of different microorganisms; they are part of a complex of environmental factors that influence the multiplication, virulence and persistence of insect pathogens. Therefore, knowing the type of interaction between cohabiting microorganisms in an ecosystem as well as the ecological effects of their coexistence is very important for fundamental studies in the field of biological control, to establish the methods to be applied. The interactions between the microorganisms existing in the soil and those introduced by the application of biopreparations greatly influence the results of biological treatments. There are 3 types of interactions between entomopathogenic microorganisms: antogonism, synergism and coexistence. The phenomenon of antagonism has been demonstrated in numerous studies comparing sterile and non-sterile soil extracts. Studies with B. bassiana suggest that inhibition of microorganisms in natural soil is caused by the fungistatic effect rather than microbial competition. It was found that patulin, a metabolite of Penicillium uriticae, was inhibitory for germination and mycelial growth of B. bassiana (Shields et al., 1981). Also, volatile metabolites of Streptomyces flavescens totally inhibited growth of some strains of B. bassiana, Paecilomyces fumosoroseus and P. farinosus while those produced by Bacillus subtilis, B. pumilus and Pseudomonas aurantiaca had only a fungistatic effect (Popowska-Nowak et al., 2003). Fungistatism, a process of strong inhibition of fungal spores germination occurs both in fungi in the natural composition of the soil and in introduced fungi. This phenomenon is found in different soils and at different depths, being more marked in soils with a large number of microorganisms and simultaneously having a food deficit. Knowledge of the interactions between B.bassiana and microorganisms existing in nature, or introduced by the application of biopreparations, is a necessary parameter for estimating the effectiveness of fungal treatments, because the survival of the B.bassiana fungus in the soil and the potential to control soil pests seem to depend more on biotic factors than on the physical ones associated with the soil. Given the well-known fact that in the case of mixed infections the phenomena of antagonism or synergism play an important role, in a series of experiments was evaluated the interaction between B.bassiana and soil microorganisms (Andrei et al., 2002; Sesan et al., 2002) with which the fungus can come into contact, namely: (I ) entomopathogenic bacterium Bacillus thuringiensis var. tenebrionis, under the conditions of practicing an integrated biological system for the protection of potato crops; (ii) entomopathogenic fungi Fusarium oxysporum and $P$. farinosus, isolated from pupae and adults of L. decemlineata, (iii) 
cohabiting micromycetes Verticillium lecanii, M. anisopliae, Trichoderma viride, frequently isolated from soil, along with B. bassiana.

Wind and precipitations. The wind can greatly alter the microclimate of a habitat and thus influence the behavior of entomopathogenic microorganisms. Millstein et al. (1983) working with Erynia spp. determined that the strongest release of spores was influenced by the lack of air currents. A wind speed of $4 \mathrm{~m} / \mathrm{min}$ and a relative humidity of $90 \%$ had the same effect on the decrease of the capacity to release spores, as in the conditions of lack of wind and a relative humidity of $75.6 \%$.

The role of precipitations on the persistence of fungal taxa possessing hydrophobic propagules in epigeal habitats was studied by Inglis et al. (1995). The authors experimentally have proven that simulated rain caused the removal of $B$. bassiana conidia from leaves of alfaalfa and wheat, with the decrease in population density ranging from 28 to $61 \%$ and, although there was a slight effect due to rain intensity for alfalfa, there was no influence of either rain duration or crop type on the retention of B. bassiana conidia. The extent to which precipitation influences the onset of an epizootic depends on the extent to which the density of conidia falls below the minimum necessary to induce mycosis in the target pest population. To reduce the impact of rain on conidial removal and prolong the time that inoculum densities remain above the threshold level, the authors the authors recommend the use of sticking agents as formulation adjuvants. Patterns of inoculum dispersal by rain and methods for monitoring pathogen inoculum are reviewed by Fitt et al. (2003).

\section{CONCLUSIONS}

The influence of environmental factors and the tolerance of microorganisms to them are of major importance for considerations of potential commercialization and field applications of entomopathogens as microbial control agents. Future research will consider the development of models that incorporate multiple influences and concomitant actions of environmental factors for a better understanding of the functioning of entomopathogens in the control of pest populations, in a proactive, preventative, rather than reactive plant protection strategy.

\section{Acknowledgement}

This work was supported by a grant of the Romanian Ministery of Research and Innovation, CCCDIUEFISCDI, project number PN-III-P1-1.2-PCCDI-2017-03-01/28PCCDI/2018, within PNCDI III

\section{REFERENCES}

ANDREI, A.M. (1998). Study of some factors that determine the effectiveness of the entomopathogenic fungus Beauveria bassiana (Bals.) Vuill. in Colorado potato beetle control. Doctoral Thesis, 176 pp., USAMV Cluj-Napoca.

ANDREI, A.M. (1998). The influence of some edaphic factors on the mycopathogen Beauveria bassiana (Bals.) Vuill. Analele I.C.P.P., 39, 113-118.

ANDREI, A.M., GALANI, G., TUDORACHE, M. (2002). Studies of Beauveria bassiana-Bacillus thuringiensis interactions in field applications for Colorado potato beetle control. 53. Deutsche Pflanzenschutztagung, 16-19 sept.2002, Bonn, Germania, 390.

BELL, J.V. (1974) Mycoses. In: Cantwell, G.E., Ed., Insect Diseases, Marcel Dekker Inc., New York, 185-236. 
BRAGA, G.U., FLINT, S.D., MILLER, C.D., ANDERSON, A.J., ROBERTS, D.W. (2001). Both solar UVA and UVB radiation impair conidial culturability and delay germination in the entomopathogenic fungus Metarhizium anisopliae. Photochemistry and Photobiology, 74, 5, 734-739. CARRUTHERS, R.I., LARKIN, T.S. SOPER, R.S. (1988). Simulation of insect disease dynamics: an application of SERB to a rangeland ecosystem. Simulation, 51, 3,101-109.

FARGUES, J., GOETTEL, M. S., SMITS, N., OUEDRAOGO, A., VIDAL, C., LACEY, L. A., ROUGIER, M. (1996). Variability in susceptibility to simulated sunlight of conidia among isolates of entomopathogenic Hyphomycetes. Mycopathologia, 135, 3, 171-181.

FARGUES, J., GOETTEL, M., SMITS, N., OUEDRAOGO, A., ROUGIER, M. (1997). Effect of temperature on vegetative growth of Beauveria bassiana isolates from different origins. Mycologia, 89, 3, 383-392. doi:10.2307/3761032.

FĂTU C., FĂTU V., ANDREI A.M. (2010). Temperature requirements in Beauveria bassiana Plodia interpunctella laboratory bioassay. Romanian Journal for Plant Protection, 3, 65-68.

FĂTU, A.C., DINU, M.M., ANDREI, A.M. (2015). Influence of different temperatures and relative humidities on in vitro germination of three entomopathogenic fungal strains of Beauveria brongniartii. Scientific Bulletin. Series F. Biotechnologies, 19, 48-51.

FERNANDES, E.K, RANGEL, D.E., MORAES, A.M., BITTENCOURT, V.R., ROBERTS, D.W. (2007). Variability in tolerance to UV-B radiation among Beauveria spp. isolates. Journal of Invertebrate Pathology, 96, 3, 237-43. doi: 10.1016/j.jip.2007.05.007.

FITT, B.D.L., McCARTNEY, H.A., WALKLATE, P. (2003). The Role of Rain in Dispersal of Pathogen Inoculum. Annual Review of Phytopathology, 27, 1, 241-270.

FUXA, J.R., TANADA, Y. (1987). Epizootiology of Insect Diseases. John Wiley \& Sons, New York, 357-416.

IBRAHIM, L., BUTT, T. M., \& JENKINSON, P. (2002). Effect of artificial culture media on germination, growth, virulence and surface properties of the entomopathogenic hyphomycete Metarhizium anisopliae. Mycological Research, 106, 6, 705-715.

IGNOFFO, C.M., GARCIA, C., HOSTETTER, D.L. and PINNEL, R.E. (1977). Vertical movement of conidia of Nomuraea rileyi through sand and loam soils. Journal of Economic Entomology, 70,163164.

IGNOFFO, C. M., GARCIA, C., HOSTETTER, D.L. (1976). Effects of Temperature on Growth and Sporulation of the Entomopathogenic Fungus Nomuraea rileyi. Environmental Entomology, 5, 5, 935936. doi:10.1093/ee/5.5.935.

IGNOFFO, C.M., GARCIA, C. (1992). Influence of conidial color on inactivation of several entomogenous fungi (hyphomycetes) by simulated sunlight. Environmental Entomology, 21, 913-917.

INGLIS, G.D., GOETTEL, M.S., JOHNSON, D.L. (1993). Persistence of the entomopathogenic fungus Beauveria bassiana on phylloplanes of crested wheatgrass and alfalfa. Biological control, 3, 258-270.

INGLIS, G.D., GOETTEL, M.S., JOHNSON, D.L. (1995). Effect of simulated rain on the persistence of Beauveria bassiana conidia on leaves of alfalfa and wheat. Biocontrol Science and technology, 5, 365-369.

INGLIS, G.D., GOETTEL, M.S., BUTT, T.M., STRASSER, H. (2001). Use of hyphomycetous fungi for managing insect pests. In: Fungi as biocontrol agents: progress, problems and potential, Butt T.M., Jackson C.W., Magan N. (eds), CAB International Wallingford, 23-69.

JARONSKI, S. T. (2010). Ecological factors in the inundative use of fungal entomopathogens.

BioControl, 55, 159-185.

KELLER, S., ZIMMERMANN, G. (1989). Mycopathogens of Soil Insects. In Insect-Fungus Interactions, N. Wilding, N.M. Collins, P.M. Hammond and J.F. Webber (eds), Academic Press, London, 239-270.

KHICK, W.B. and PARKINSON, D. (1990). Soil fungi. In Soil Biology Guide, Ed. D.L. Dindal, John Wiley \& Sons, New York, 49-68,

KHACHATOURIANS, G.G. (1991). Physiology and genetics of entomopathogenic fungi. In Handbook of Applied Mycology, Arora DK, Ajello L, Mukerji KG, (eds.), Marcel Dekker Inc, New York, 2, 613-664. 
KIEWNICK, S. (2006). Effect of temperature on growth, germination, germ-tube extension and survival of Paecilomyces lilacinus strain 251. Biocontrol Science and Technology, 16, 535-546. doi: 10.1080/09583150500532766.

LUZ, C., FARGUES, J. (1997). Temperature and moisture requirements for conidial germination of an isolate of Beauveria bassiana, pathogenic to Rhodnius prolixus. Mycopathologia, 138, 117-125.

MILLSTEIN, J., BROWN G., NORDIN G.L. (1983). Microclimatic Moisture and Conidial Production in Erynia sp. (Entomophthorales: Entomophthoraceae): In vivo production rate and duration under constant and fluctuating moisture regimes. Environmental Entomology, 12, 5, 13441349.

MATAWELE P., TRINCI A.P.J., GILLESPIE, A.T. (1994). Mutants of entomopathogenic fungi that germinate and grow at reduced water activities and reduced relative humidities are more virulent to Nephotettix virescens (green leafhopper) than the parental strains. Mycological Research, 98, 11, 1329-1333.

MCCAMMON, S.A., RATH, A.C. (1994). Separation of Metarhizium anisopliae strains by temperature dependent germination rates. Mycological Research, 98, 11, 1253-1257.

PADMINI, P.C.P., PADMAJA, V. (2010). Impact of different relative humidities on in vitro growth and sporulation of entomopathogenic fungal isolates of Beauveria species. International Journal of Pharmaceutical, Chemical and Biological Sciences, 1, 355-359.

POPOWSKA, N.E. (2003). Interactions between soil microorganisms: bacteria, actinomycetes and entomopathogenic fungi of the genera Beauveria and Paecilomyces. Polish Journal of Ecology, 51, 1, $85-90$.

ROBERTS, D.W. and CAMPBELL, A.S. (1977). Stability of entomopathogenic fungi. Miscellaneous Publications of the Entomological Society of America 10, 19-76.

RUIU, L. (2018). Microbial Biopesticides in Agroecosystems. Agronomy, 8, 235 doi: 10.3390/agronomy8110235.

SABBAHI, R., MERZOUKI, A., \& GUERTIN, C. (2008). Efficacy of Beauveria bassiana against the strawberry pests, Lygus lineolaris, Anthonomus signatus and Otiorhynchus ovatus. Journal of Applied Entomology, 132, 2, 151-160.

SESAN, T. E., CONSTANTINESCU F., ANDREI, A.M., KUPFERBERG, S., DINU, S. (2002). In vitro relationships between microorganisms used as biocontrol agents. IOBC/WPRS Bulletin "Biological Control of Fungal and Bacterial Plant Pathogens", Proceedings of the Seventh WG Meeting (Influence of A-biotic and Biotic Factors on Biocontrol agents), Pine Bay, Kusadasi, Turkey, 22-25 mai 2002, $25,10,345-348$.

SHIELDS, MS., LINGG, A.J., HEIMSCH, RC. (1981). Identification of a Penicillium urticae metabolite which inhibits Beauveria bassiana. Journal of Invertebrate Pathology, 38, 3, 374-777.

STEINKRAUS, D.C., SLAYMAKER, P.H. (1994). Effect of temperature and humidity on formation, germination and infectivity of conidia of Neozygites fresenii from Aphis gossypii. Journal of Invertebrate Pathology, 64, 130-137.

STUDDERT, J. P., \& KAYA, H. K. (1990). Water potential, temperature, and soil type on the formation of Beauveria bassiana soil colonies. Journal of Invertebrate Pathology, 56, 3, 380-386.

STOREY, G.K. and GARDNER, W.A. (1988). Movement of an aqueous spray of Beauveria bassiana into the profile of four Georgia soils. Environmental Entomology 17, 135-139.

TANADA, Y., KAYA, HY. (1993). Insect Pathology. Academic Press, New York, USA.

VAN DER VALK, H. (2007). Review of the efficacy of Metarhizium anisopliae var. acridum against the desert locust. Desert Locust Technical Series. FAO, Rome. Available from: http://www.fao.org/ag/locusts/common/ecg/1295/en/TS34e.pdf.

YIP, H.Y., RATH, A.C., KOEN, T.B. 1992. Characterization of Metarhizium anisopliae isolated from Tasmanian pasture soils and their pathogenicity to redheaded pasture cockchafer (Coleoptera: Scarabaeidae: Adoryphous couloni). Mycological Research, 96, 92-96. ZIMMERMANN, G. (2007). Review on safety of the entomopathogenic fungi Beauveria bassiana and Beauveria brongniartii. Biocontrol Science and Technology, 17, 553-596. 